\title{
Pengaruh Digital Marketing Pada Peningkatan Brand Awareness Dan Brand Image Terhadap Keputusan Pembelian Produk Cokelat Monggo di Yogyakarta
}

\author{
Hafizh Fitrianna \\ Universitas Negeri Yogyakarta \\ Derista Aurinawati \\ Universitas Islam Indonesia \\ hafizh.fitrianna@uny.ac.id
}

\begin{abstract}
Abstrak
Beberapa lokasi di Yogyakarta memiliki peninggalan bangunan kebudayaan yang menarik bagi wisatawan baik lokal maupun mancanegar. Pengelolaan Pariwisata meliputi fasilitas transportasi dan akomodasi dan yang tertata baik dapat menjadi faktor pendukung bagi daerah wisata untuk mampu menarik minat wisatawan. Dengan berkembangnya teknologi saat ini, pengenalan keunggulan daerah wisata (brand awareness dan brand image) dapat menggunakan platform media online yang saat ini sudah banyak digunakan seperti instagram, facebook, google ads, dan aplikasi online lainnya. Tujuan penelitian ini untuk mengetahui pengaruh digital marketing (baik melalui sosial media maupun dengan media pemasaran online lain) pada peningkatan brand awareness dan brand image terhadap keputusan pembelian produk Cokelat Monggo yang ada di Yogyakarta. Penelitian ini menggunakan metode kuantitatif dengan 200 sampel. Untuk menguji validitas dan reliabilitas menggunakan software SPSS versi 23. Hasil penelitian ini menunjukkan bahwa pemasaran melalui media digital berpengaruh secara signifikan untuk meningkatkan brand awareness dan brand image sehingga dapat mempengaruhi keputusan pembelian produk Cokelat Monggo yang ada di Yogyakarta. Hasil penelitian dapat dipergunakan untuk membangun strategi pemasaran online agar memiliki dampak yang tinggi dalam meningkatkan respon konsumen dengan menggunakan pendekatan tiga buah variabel (digital marketing, brand awareness, dan brand image).
\end{abstract}

Kata kunci : brand awareness, brand image, digital marketing

\section{Pendahuluan}

Saat ini Yogyakarta merupakan destinasi wisata yang pengelolaannya semakin baik, sehingga mampu menarik minat wisatawan untuk datang berkunjung. Data dari Dinas Pariwisata Kota Yogyakarta menyatakan bahwa kunjungan wisatawan nusantara (wisnus) dan wisatawan mancanegara (wisman) di kota Gudeg ini menunjukkan peningkatan dari tahun ke tahun. Pada rentang waktu 2016 sampai 2019, jumlah wisatawan mencapai angka empat juta orang dengan rincian 2016 sebanyak 3,5 juta, 2017 di angka 3,8 juta, serta 2018 sejumlah 4,1 juta. Pada 2016, jumlah wisman tercatat sebanyak 396.518 orang dan 3.150 .834 wisnus, 2017 ada sebanyak 435.655 wisman dan 3.459.116 wisnus yang berkunjung, serta 496.293 wisnus dan 3.606 .947 wisnus pada 2018. Banyak lokasi di Yogyakarta memiliki peninggalan bangunan kebudayaan jawa masa lalu yang saat ini menjadi destinasi wisata yang cukup menarik bagi wisatawan baik lokal maupun mancanegara, seperti Tamansari, Keraton Ngayogyakarta, Museum Benteng Vredeburg, 


\section{Hafizh Fitriana, Derista Aurinawati}

Masjid Besar Mataram, Makam Panembahan Senopati, Plengkung Gading, Pojok Benteng dan banyak bangunan peninggalan sejarah lainnya. Fasilitas transportasi dan akomodasi yang tertata baik dapat menjadi faktor pendukung bagi daerah wisata untuk mampu menarik minat wisatawan.

Dengan semakin banyaknya wisatawan yang berkunjung ke Yogyakarta mampu mendongkrak perekonomian lokal masyarakat melalui sektor usaha transportasi, akomodasi dan pengelola wisata. Salah satu hal yang menjadi daya tarik kunci suatu daerah wisata mampu menjadi tujuan wisata favorit adalah adanya suatu produk khas dari daerah tersebut. Objek dari penelitian ini adalah produk dari Cokelat Monggo yang merupakan satu produk olahan cokelat yang diproduksi dan dipasarkan terpusat di Yogyakarta. Setiap pengunjung/wisatawan yang berkunjung ke Yogyakarta biasanya akan mencari oleh-oleh untuk dibawa ke daerah asalnya dengan tujuan untuk membawakan buah tangan bagi keluarga atau kerabatnya. Produk Cokelat Monggo merupakan satu brand yang telah cukup dikenal di masyarakat luas karena reputasinya sebagai produk olahan dengan bahan dasar cokelat telah diakui kualitasnya.

Pemanfaatan teknologi digital dan media sosial saat ini sudah menjadi fenomena tersendiri. Berbagai aktivitas masyarakat telah menjadi obyek unggahan di media sosial yang dapat dilihat dari berbagai penjuru daerah. Dengan kelebihan media sosial yang mampu diakses secara realtime dan tidak terbatas wilayah, merupakan suatu keuntungan yang dapat dimanfaatkan untuk kepentingan usaha, dalam hal ini berfungsi untuk memasarkan produk (Thamwika, 2013). Produsen dapat mengenalkan produknya agar mendapat perhatian lebih dari calon konsumennya (brand awareness dan brand image) sehingga harapan terjadinya pembelian produk oleh konsumen semakin tinggi. Penggunaan media digital dan media sosial telah mampu menggeser tren pemasaran yang sebelumnya menggunakan media konvensional/cetak menjadi digital marketing.

Datareportal.com. (18 Februari 2020). Digital 2020 Indonesia. Diakses pada 18 September 2020, dari https://datareportal.com/reports/digital-2020-indonesia menunjukkan ada 79 juta akun media sosial yang aktif di Indonesia, meningkat 10\% dari Januari 2015. Sedangkan sejak Januari 2015 hingga Januari 2016, jumlah pengguna internet di Indonesia meningkat sekitar $15 \%$. Berdasarkan data dari website tersebut juga menyatakan data pada tahun 2015 di Indonesia ada 38 juta pengguna internet dan setidaknya minimal sekali dalam satu bulan $79 \%$ diantaranya aktif di media sosial. Media sosial dapat berguna untuk mendukung proses pemasaran hanya jika social media marketers-nya paham tentang karakteristik media sosial yang digunakan dengan hubungannya pada bisnis yang sedang direpresentasikan. Setiap sosial media memiliki karakteristik yang berbeda sesuai dengan industri bisnis yang dijalankan (Humaira, et.al, 2016).

Sesuai data yang disajikan, dengan semakin meningkatnya pengguna media sosial pada masyarakat Indonesia merupakan suatu peluang yang dapat dimanfaatkan oleh pemilik usaha atau perusahaan untuk memasarkan produk atau jasanya melalui media sosial. Penggunaan media digital sebagai media pemasaran juga telah merambah pada usaha Cokelat Monggo melalui penggunaan website, media sosial perusahaan dan juga penjualan melalui marketplace yang ada.

\section{Landasan Teori}

Mohammed, Fisher, Jaworski, \& Paddison (2003), e-marketing adalah proses membangun dan memelihara hubungan dengan pelanggan melalui aktivitas secara online untuk memfasilitasi pertukaran ide-ide, produk-produk, dan pelayanan yang memberikan 


\section{Hafizh Fitriana, Derista Aurinawati}

kepuasan kepada kedua belah pihak. Sedangkan menurut Julisar (2013) pemanfaatan internet memungkinkan Usaha Kecil dan Menengah melakukan pemasaran dengan tujuan pasar global, sehingga peluang menembus ekspor sangat mungkinImplementasi dari e-commerce juga harus didukung dengan adanya sistem pembayaran danpemenuhan pemesanan dari pembeli,yaitu suatu portal yang berisikan konten dari perusahaan tersebut. Media sosial adalah kumpulan aplikasi yang berbasis pada internet yang didirikan atas dasar teknologi web 2.0, dan memperkenankan pengguna untuk mengisi kontennya. Media sosial akan berhenti jika tidak ada pengguna yang mengisi kontennya. Adapun ciri-ciri dari media sosial yaitu pesan yang disampaikan tidak hanya untuk satu orang saja namun bisa keberbagai banyak orang, pesan yang disampaikan cenderung lebih cepat dibandingkan dengan media lainnya, adanya interaksi dengan banyak pihak sehingga membuat media ini lebih hidup. Media sosial dapat berbentuk forum, microblogging, social networking, social bookmarking, dan wiki. (Kaplan Andreas, 2010:269). Komponen media sosial juga telah dibahas dalam studi dengan berbagai penulis dan pengaturan. Kim dan Ko (2012) mendefinisikan social media marketing diterapkan perusahaan untuk membangun kesadaran merek-merek mereka. Lee (2017) mengatakan bahwa kegiatan media sosial perusahaan berfungsi dalam komunikasi, memberikan informasi, dukungan untuk kehidupan sehari-hari, promosi dan penjualan, dan respon sosial. Dengan hadirnya media sosial juga dapat digunakan sebagai alat bagi perusahaan untuk mengkomunikasikan keunikan merek mereka dan meningkatkan preferensi untuk dan kesetiaan kepada merek-merek (Martin dan Todorov, 2010).

\section{Brand Awareness}

Brand awareness berkaitan dengan kekuatan merek di dalam benak konsumen yang dapat diukur melalui kemampuan konsumen untuk mengidentifikasi merek dalam kondisi yang bervariasi. Kotler dan Armstrong (2012) menyatakan bahwa perusahaan harus mengelola merek produk mereka dengan baik. Pemasar merek besar sering menghabiskan uang dengan jumlah besar untuk iklan yang bertujuan menciptakan brand awareness dan brand loyalty. Kampanye iklan dapat membantu menciptakan brand recognition, brand knowledge, dan brand preference (Mor, 2017). Namun, kenyataannya merek tidak dikelola oleh iklan, tetapi dengan brand experience pelanggan. Saat ini, pelanggan datang untuk mengetahui merek melalui berbagai media termasuk iklan, tetapi juga pengalaman pribadi dengan merek, dari mulut ke mulut, webpage perusahaan, dan banyak lainnya. Bruhn, Schoenmueller dan Schafer (2012:770- 790) mengatakan bahwa penggunaan media sosial memungkinkan perusahaan untuk meningkatkan brand awarenss mereka. Penggunaan media sosial menambah nilai atraktivitas dari sebuah merek dan menambah tingkat kedekatan konsumen dengan merek tersebut. Karena itu, banyak perusahaan kini menerapkan strategi untuk mempengaruhi tingkat keterlibatan komunikasi merek antarkonsumen (As'ad, 2014). Dengan demikian, mereka menciptakan nilai atraktivitas dan keinginan konsumen untuk membeli produk tersebut. Penggunaan media sosial juga memungkinkan perusahaan untuk mengumpulkan pemikiran konsumen terhadap produk atau jasa yang mereka tawarkan, mulai dari preferensi konsumen, kelebihan produk, hingga kelemahan produk. (Yoon, 2012)

\section{Brand Image}

Brand image merupakan efek diferensial untuk mengetahui apakah nama merek telah di respon pelanggan terhadap produk dan pemasaran (Sano, 2015). Ini adalah ukuran kemampuan merek untuk menangkap tanggapan dan loyalitas konsumen. Sebuah merek 


\section{Hafizh Fitriana, Derista Aurinawati}

memiliki brand image positif ketika konsumen bereaksi lebih baik daripada versi generik atau tanpa merek dari produk yang sama (Kotler dan Armstrong, 2012). Brand image menurut American Marketing Association dikatakan sebagai bentuk refleksi cerminan dari suatu brand personality merek yang dikonsumsi, sehingga brand image merupakan suatu hal yang dipercayai konsumen terhadap brand yang digambarkan melalui pikiran, perasaan dan harapan mereka. Kaplan (2010) mengatakan bahwa sosial media memiliki pengaruh terhadap proses branding. Saat pemasar menemui para konsumennya maka si pemasar harus melakukan percakapan yang semakin dalam, sehingga dari percakapan tersebut brand yang dibawanya akan semakin kuat, namun apabila pemasar hanya melakukan percakapan pendek dan tidak memberikan kesan kepada konsumen maka bisa jadi brand yang dibawanya menjadi lemah. (Zhang, et.al. 2015)

\section{Keputusan Pembelian}

Dalam membeli dan mengkonsumsi sesuatu terlebih dahulu konsumen membuat keputusan mengenai produk apa yang dibutuhkan, kapan, bagaimana dan dimana proses pembelian atau konsumsi itu akan terjadi (Tsitsi, 2013). Dengan kata lain diperlukan suatu proses pengambilan keputusan untuk membeli sesuatu baik barang atau jasa. Menurut Yoestini (2007), pengambilan keputusan yang diambil oleh seseorang dapat disebut sebagai suatu pemecahan masalah. Dalam proses pengambilan keputusan, konsumen memiliki sasaran atau perilaku yang ingin dicapai atau dipuaskan. Selanjutnya konsumen membuat keputusan perilaku mana yang ingin dilakukan untuk mencapai sasaran tersebut.

Menurut Kotler (2005) Keputusan pembelian adalah suatu tahap dimana konsumen telah memiliki pilihan dan siap untuk melakukan pembelian atau pertukaran antara uang dan janji untuk membayar dengan hak kepemilikan atau penggunaan suatu barang atau jasa. Yang dimaksud dengan keputusan pembelian adalah suatu proses penyelesaian masalah yang terdiri dari menganalisa atau pengenalan kebutuhan dan keinginan hingga perilaku setelah pembelian (Indrawijaya, 2012)

\section{Pengembangan Hipotesis}

Korelasi antar variabel yang digunakan untuk pengembangan hipotesis pada penelitian ini dapat dijelaskan sebagai berikut :

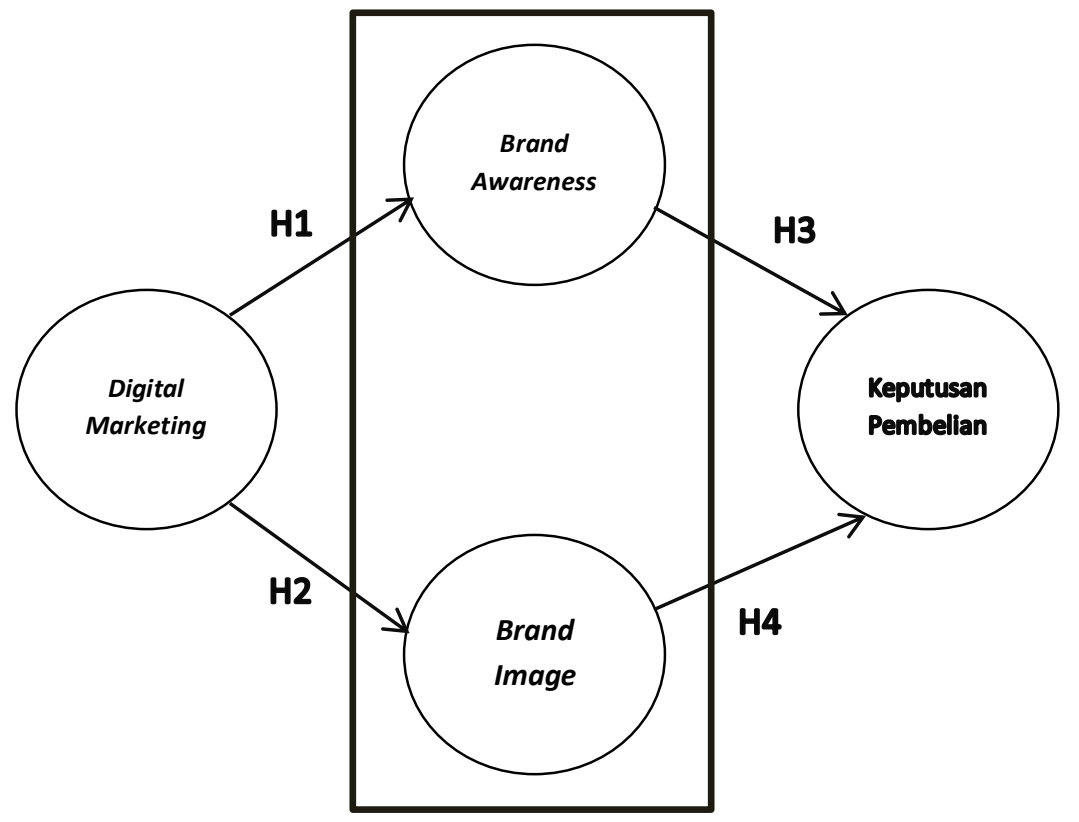


Hipotesis $1 \quad$ : Digital marketing berpengaruh terhadap brand awareness

Hipotesis 2 : Digital marketing berpengaruh terhadap brand image

Hipotesis 3 : Brand awareness berpengaruh terhadap keputusan pembelian

Hipotesis 4 : Brand image berpengaruh terhadap keputusan pembelian

\section{Metode Penelitian}

Survei ini dilakukan dengan metode convenience sampling di Showroom \& Gallery Cokelat Monggo yang ada di Kotagede Yogyakarta. Teknik pengumpulan data dalam penelitian ini menggunakan metode penyebaran kuesioner. Kuesioner didistribusikan langsung kepada subjek penelitian dan kemudian dikumpulkan setelah responden menjawab. Jumlah responden penelitian ini sebanyak 200. Skala Likert 1-5 digunakan dalam penelitian ini yang terbagi menjadi 5 yaitu (1) Sangat Tidak Setuju, (2) Tidak Setuju, (3) Netral, (4) Setuju, (5) Sangat Setuju. Uji Validitas dan Uji Reliabilitas Instrumen penelitian menggunakan aplikasi SPSS Versi 23.

\section{Pembahasan}

\section{Uji Validitas}

Uji Validitas merupakan kemampuan dari construct indicator yang di gunakan untuk mengukur tingkat keakuratan sebuah kuesioner. Artinya apakah kuesioner yang telah dibuat tersebut sudah akurat atau belum. Jika sudah akurat, maka kuesioner tersebut dapat dilanjutkan. Namun sebaliknya, jika kuesioner tersebut belum akurat maka perlu dilakukan pengujian ulang (Ferdinand, 2002). Pengujian dilakukan dengan cara mengkorelasikan setiap butir pertanyaan dengan skor total kemudian intepretasi dari koefisien korelasi yang dihasilkan, koefisien korelasi yang dihasilkan lalu dibandingkan dengan r-table. Jika korelasi antara r-hitung lebih kecil dari r-table, maka intrumen dinyatakan tidak valid. Namun jika rhitung lebih besar dari r-table maka dinyatakan valid. Dalam penelitian ini r-table adalah 0.312 dengan tingkat signifikansi 0.05 .

\section{Instrumen Digital Marketing}

\begin{tabular}{|c|c|c|c|c|}
\hline Butir & r-hitung & r-table & $\mathbf{p}$ & Keterangan \\
\hline EN1 & 0.683 & 0.3120 & 0.000 & Valid \\
\hline EN2 & 0.808 & 0.3120 & 0.000 & Valid \\
\hline EN3 & 0.581 & 0.3120 & 0.000 & Valid \\
\hline EN4 & 0.691 & $\mathbf{0 . 3 1 2 0}$ & $\mathbf{0 . 0 0 0}$ & Valid \\
\hline EN5 & 0.360 & 0.3120 & 0.000 & Valid \\
\hline
\end{tabular}


INOBIS: Jurnal Inovasi Bisnis dan Manajemen Indonesia

Volume 03, Nomor 03, Juni 2020

Hafizh Fitriana, Derista Aurinawati

2. Instrumen Brand Awareness

\begin{tabular}{|c|c|c|c|c|}
\hline Butir & r-hitung & r-table & $\mathbf{p}$ & Keterangan \\
\hline PI1 & 0.848 & 0.3120 & 0.000 & Valid \\
\hline PI2 & 0.899 & 0.3120 & 0.000 & Valid \\
\hline PI3 & 1 & 0.3120 & 0.000 & Valid \\
\hline
\end{tabular}

3. Instrumen Brand Image

\begin{tabular}{|c|c|c|c|c|}
\hline Butir & r-hitung & r-table & $\mathbf{p}$ & Keterangan \\
\hline MI1 & 0.915 & 0.3120 & 0.000 & Valid \\
\hline MI2 & 0.908 & 0.3120 & 0.000 & Valid \\
\hline MI3 & 1 & 0.3120 & 0.000 & Valid \\
\hline
\end{tabular}

4. Instrumen Keputusan Pembelian

\begin{tabular}{|c|c|c|c|c|}
\hline Butir & r-hitung & r-table & $\mathbf{p}$ & Keterangan \\
\hline EI1 & 0.907 & 0.3120 & 0.000 & Valid \\
\hline EI2 & 0.865 & 0.3120 & 0.000 & Valid \\
\hline EI3 & 1 & 0.3120 & 0.000 & Valid \\
\hline
\end{tabular}

\section{Uji Reliabilitas}

Uji reliabilitas (reliability) menunjukkan sejauh mana suatu alat ukur yang dapat di gunakan untuk memberikan hasil yang relatif sama apabila melakukan pengukuran kembali pada subyek yang sama (Ferdinand, 2002). Suatu instrumen penelitian dikatakan reliable jika nilai koefisien reliabilitasnya lebih dari 0.60 . Hasil pengujian reliabilitas ini menggunakan SPSS V23 tertera pada table dibawah ini :

\begin{tabular}{|c|c|c|c|}
\hline No. & Instrument & $\begin{array}{c}\text { Cronbach,s } \\
\text { Alpha }\end{array}$ & Keterangan \\
\hline 1 & Digital Marketing & 0.615 & Reliabel \\
\hline 2 & Brand Awareness & 0.685 & Reliabel \\
\hline 3 & Brand Image & 0.797 & Reliabel \\
\hline 4 & Keputusan Pembelian & 0.885 & Reliabel \\
\hline
\end{tabular}




\section{Goodness of Fit Model}

Menilai goodness of fit digunakan untuk mengetahui sampai seberapa jauh model yang dihipotesiskan "Fit" atau cocok dengan sampel data. Hasil goodness of fit ditampilkan pada data berikut ini:

\begin{tabular}{|l|l|l|l|}
\hline $\begin{array}{c}\text { Goodness offit } \\
\text { index }\end{array}$ & Cut-off value & $\begin{array}{c}\text { Model } \\
\text { Penelitian }\end{array}$ & Model \\
\hline Chi-square & $\begin{array}{l}\text { Diharapkan } \\
\text { kecil }\end{array}$ & 474,120 & Marginal \\
\hline $\begin{array}{l}\text { Significant } \\
\text { probability }\end{array}$ & $\geq 0.05$ & 0,000 & Marginal \\
\hline RMSEA & $\leq 0.08$ & 0,052 & Fit \\
\hline GFI & $\geq 0.90$ & 0,844 & Marginal \\
\hline AGFI & $\geq 0.90$ & 0,815 & Marginal \\
\hline CMIN/DF & $\leq 2.0$ & 1,491 & Fit \\
\hline TLI & $\geq 0.90$ & 0,953 & Fit \\
\hline CFI & $\geq 0.90$ & 0,957 & Fit \\
\hline
\end{tabular}

Berdasarkan Hasil pada di atas, dapat dilihat bahwa model penelitian mendekati sebagai model good fit. CMIN/DF merupakan indeks kesesuaian parsiomonious yang mengukur goodness of fit model dengan jumlah koefisien-koefisien estimasi yang diharapkan untuk mencapai kesesuaian. Hasil CMIN/DF pada penelitian ini 1,491 menunjukan bahwa model penelitian fit. Goodness of Fit Indeks (GFI) menunjukan tingkat kesesuaian mdel secara keseluruhan yang dihitung dari residual kuadrat dari model yang diprediksi dibandingkan data sebenarnya. Nilai GFI pada model ini adalah 0,844 . Nilai mendekati dengan tingkat yang direkomendasikan $\geq 0,90$ menunjukkan model penelitian marginal fit.

RMSEA adalah indeks yang digunakan untuk mengkompensasi nilai chi-square dalam sampel yang besar. Nilai RMSEA penelitian ini adalah 0,052 dengan nilai yang direkomendasikan yaitu $\leq 0,08$. Hal ini menunjukkan model penelitian fit. AGFI adalah GFI yang disesuaikan dengan rasio antara degree of freesom yang diusulkan dan degree of freedom dari null model. Nilai AGFI pada model ini adalah 0,815. Nilai mendekati dengan tingkat yang direkomendasikan $\geq 0,90$ menunjukkan model penelitian marginal fit TLI merupakan imdeks kesesuaian yang kurang dipengarui ukuran sampel. Nilai TLI pada penelitian ini adalah 0,953 dengan nilai yang direkomendasikan yaitu $\geq 0,90$ hal inimenunjukkan model penelitian fit. CFI merupakan indeks yang relative tidak sensitif terhadap besarnya sampel dan kerumitan model. Nilai CFI pada penelitian ini adalah 0,957 dengan nilai yang direkomendasikan yaitu $\geq 0,90$ hal inimenunjukkan model penelitian fit. Berdasarkan keseluruhan pengukuran goodness of fit diatas mengindikasi bahwa model yang diajukan dalam penelitian ini diterima.

\section{Uji Hipotesis}

Proses pengujian statistik ini dapat dilihat pada tabel di bawah ini. Dari pengolahan data diketahui bahwa nilai CR terdapat hubungan dengan menunjukkan nilai di atas 1,96 untuk CR dan di bawah 0,05 untuk nilai p (Ghozali, 2014), dengan demikian dapat dikatakan bahwa : Pengujian hipotesis yang dilakukan adalah untuk menjawab pertanyaan-pertanyaan pada penelitian ini atau menganalisis hubungan-hubungan structural model. Analisis data 


\section{Hafizh Fitriana, Derista Aurinawati}

hipotesis dapat dilihat dari nilai standardized regression weight yang menunjukkan koefisien pengaruh antar variable dalam tabel berikut :

Tabel Hubungan Antar Variabel

\begin{tabular}{|c|c|c|c|c|c|c|c|}
\hline & & & Estimate & S.E. & C.R. & P & Hipotesis \\
\hline $\begin{array}{c}\text { Brand } \\
\text { Awareness }\end{array}$ & $<---$ & $\begin{array}{c}\text { Digital } \\
\text { Marketing }\end{array}$ &, 817 &, 091 & 8,951 & 0,000 & $\begin{array}{c}\text { Positif } \\
\text { Signifikan }\end{array}$ \\
\hline Brand Image & $<---$ & $\begin{array}{c}\text { Digital } \\
\text { Marketing }\end{array}$ &, 984 &, 096 & 10,271 & 0,000 & $\begin{array}{c}\text { Positif } \\
\text { Signifikan }\end{array}$ \\
\hline $\begin{array}{c}\text { Keputusan } \\
\text { Pembelian }\end{array}$ & $<---$ & $\begin{array}{c}\text { Brand } \\
\text { Awereness }\end{array}$ &, 359 &, 128 & 2,813 & 0,005 & $\begin{array}{c}\text { Positif } \\
\text { Signifikan }\end{array}$ \\
\hline $\begin{array}{c}\text { Keputusan } \\
\text { Pembelian }\end{array}$ & $<---$ & Brand Image &, 299 &, 126 & 2,384 & 0,017 & $\begin{array}{c}\text { Positif } \\
\text { Signifikan }\end{array}$ \\
\hline
\end{tabular}

Berdasarkan tabel di atas dapat dijelaskan hubungan antar variabel.

1) Pengaruh digital marketing terhadap brand awareness. Parameter estimasi nilai koefisien standardized regression weight diperoleh sebesar 0,817 dan nilai C.R 8,951 Hal ini menunjukan bahwa hubungan penggunaan digital marketing dengan peningkatan brand awareness positif. Artinya, semakin baik pemanfaatan digital marketing dalam proses pemasaran yang dilakukan oleh Cokelat Monggo, maka mampu meningkatan brand awareness. Pengujian hubungan kedua variabel tersebut menunjukkan nilai probabilitas $0,000(\mathrm{p}<0,05)$, sehingga $(\mathrm{H} 1)$ yang menyatakan "Digital marketing berpengaruh positif terhadap brand awareness" terdukung dan dapat dinyatakan jika ada pengaruh secara langsung antara digital marketing dengan brand awareness.

2) Pengaruh digital marketing terhadap brand image. Parameter estimasi nilai koefisien standardized regression weight diperoleh sebesar 0,984 dan nilai C.R 10,271 hal ini menunjukan bahwa hubungan antara penggunaan digital marketing dengan efek penguatan brand image positif. Artinya semakin baik digital marketing yang dikakukan, maka dapat meningkatan brand image di mata konsumen Cokelat Monggo. Pengujian hubungan kedua variabel tersebut menunjukkan nilai probabilitas $0,000(\mathrm{p}<0,05)$, sehingga $(\mathrm{H} 2)$ yang berbunyi "Digital marketing berpengaruh positif terhadap brand image" terdukung dan dapat dinyatakan jika ada pengaruh secara langsung antara digital marketing dengan brand image.

3) Pengaruh brand awareness terhadap keputusan pembelian. Parameter estimasi nilai koefisien standardized regression weight diperoleh sebesar 0,359 dan nilai C.R 2,813 hal ini menunjukan bahwa hubungan brand awareness dengan keputusan pembelian menunjukkan nilai positif. Artinya semakin baik brand awareness produk Cokelat Monggo di mata konsumen maka akan meningkatan keputusan pembelian produknya. Pengujian hubungan kedua variabel tersebut menunjukkan nilai probabilitas 0,005 $(\mathrm{p}<0,05)$, sehingga (H3) yang berbunyi "Brand awareness berpengaruh positif pada keputusan pembelian" terdukung dan dapat dinyatakan jika ada pengaruh secara langsung antara brand awareness dengan keputusan pembelian.

4) Pengaruh brand image terhadap keputusan pembelian. Parameter estimasi nilai koefisien standardized regression weight diperoleh sebesar 0,636 dan nilai C.R 5,128 hal ini menunjukan bahwa hubungan brand image dengan keputusan pembelian positif. Artinya, semakin baik brand image produk Cokelat Monggo yang dirasakan 


\section{Hafizh Fitriana, Derista Aurinawati}

oleh konsumen, maka akan meningkatan keputusan pembelian. Pengujian hubungan kedua variabel tersebut menunjukkan nilai probabilitas $0,000(\mathrm{p}<0,05)$, sehingga $(\mathrm{H} 4)$ yang berbunyi "Brand Image berpengaruh positif pada keputusan pembelian" terdukung dan dapat dinyatakan jika ada pengaruh secara langsung antara brand image dengan keputusan pembelian.

\section{Kesimpulan}

Penelitian ini meneliti tentang pengaruh penggunaan digital marketing pada produk Cokelat Monggo pada dua jenis ekuitas merek, yaitu kesadaran merek (brand awareness) dan citra merek (brand image) terhadap keputusan pembelian konsumen. Kesimpulan dari penelitian yang dilakukan yaitu Semua instrumen pada variabel digital marketing, kesadaran merek (brand awareness), citra merek (brand image) dan keputusan pembelian telah diuji validitas, dan memiliki hasil valid di atas 0.312, dimana hasil dari r-hitung lebih besar dari pada r-tabel. Hal ini menyatakan bahwa butir pertanyaan kueisoner yang diajukan oleh peneliti valid. Semua instrumen pada variabel digital marketing, brand awareness (kesadaran merek), brand image (citra merek) dan keputusan pembelian pada uji reliabilitas memiliki hasil yang siginifikan, dimana semua butir pertanyaan kuesioner diajukan yang dilakukan oleh peneliti memiliki nilai diatas 0.60 yang artinya instrumen pertanyaan yang diajukan reliable atau memiliki hasil yang signifikan. Penggunaan konsep digital marketing berpengaruh positif pada brand awareness (kesadaran merek) dan brand image (citra merek) pada produk Cokelat Monggo. Secara keseluruhan penelitian ini menyatakan bahwa penggunaan digital marketing berpengaruh positif pada keputusan pembelian oleh konsumen.

Saran yang dapat diberikan dari hasil penelitian ini antara lain : 1) Strategi pemasaran produk Cokelat Monggo harus dioptimalkan dengan pemanfaatan teknologi agar mampu menjangkau pangsa pasar yang lebih luas; 2) Penggunaan konsep pemasaran yang mampu meningkatkan brand awareness dan brand image perlu untuk dikonsep lebih mendalam; 3) Penelitian selanjutnya mampu menambahkan variabel lain agar dapat mendapatkan hasil penelitian yang lebih mendalam.

\section{Daftar Pustaka}

As'ad, H. Abu Rumman \& Anas Y. Alhadid, 2014. "The Impact of Social Media Marketing on Brand Equity: An Empirical Study on Mobile Service Providers in Jordan”, Review of Integrative Business and Economics Research, vol. 3:1,

Bruhn, M., Schoenmueller, V \& Shaefer, D.B. 2012. Are social media replacing traditional media in term of brand equity creaction. Managemenr Research Review, 35(9), 770790

Digital 2020 Indonesia. Februari 2020. Diakses pada 18 September 2020, dari https://datareportal.com/reports/digital-2020-indonesia

Ferdinand, Augusty, 2006. "Structural Equation Modelling Dalam Penelitian Manajemen”. Badan Penerbit UNDIP Semarang.

Ghozali, I. (2014). Structural equation modeling, metode alternatif dengan Partial Least Square (PLS). (4th ed). Semarang: Universitas Diponegoro

Humaira et al. 2016. "Analisis Faktor Elektronik Word Of Mouth (E-wom) Dalam Mempengaruhi Keputusan Berkunjung Wisatawan"

Julisar \& Miranda Eka, 2013. Pemakaian E-Commerce untuk Usaha Kecil dan Menengah Guna Meningkatkan Daya Saing. Jakarta:Binus University. 


\section{Hafizh Fitriana, Derista Aurinawati}

Indrawijaya, Sigit. (2012). "Pengaruh Kualitas Produk \& Word of Mouth terhadap Keputusan Konsumen dalam Pembelian Roti Manis pada Industri Kecil di Kabupaten Sarolangun". Jurnal Mankeu Universitas Jambi Vol. 1, No. 3, 2012: 193-208.

Kaplan, A. M., \& Haenlein, M. 2010. Users of The World, Unite! The Challenges and Opportunities of Social Media. The International Journal on Media Management

Kim, A.J.,\& Ko, E., 2012. Do social media marketing activities enhance customer equity ? An empirical study of luxury fashion brand. J. Bus. Res. 65 (10), 1480-1486.

Kotler, Philip and Gray Armstrong, 2012. Prinsip-Prinsip Pemasaran. Edisi 13. Jilid 1. Jakarta : Erlangga

Kotler. 2012. Manajemen Pemasaran Perspektif Asia. Buku Dua, Edisi Pertama. Andy, Yogyakarta.

Lee, S., 2017. A Study on Different Recognition of Importance in Enterprises Social Media Activites Based on Comparasion between Cunsumer and Enterprises : Focusing on Commercial and Relational Characteristics of Activity Types. Master's dissertation Hankuk University of Foreign Studies.

Mohammed, R.A., Fisher, R.J., Jaworski, B.J., Paddison, G.J. 2003. Internet Marketing: Building Advantage in A Networked Economy. New York : McGraw Hill,Inc.

Mor, Nina Yunita. 2017.”Pengaruh Beauty Vlogger Sebagai Celebrity Endorser Terhadap Niat Beli Dengan Asosiasi Merek Sebagai Intervening Variabel". Skripsi. Universitas Sanata Dharma.

Sano, K., 2015. An empirical study the effect of social media marketing activities upon customer satisfaction, positive word-of-mouth and commitment in indemnity insurance service. In: Proceedings International Marketing Trends Conference.

Thamwika Bergstrom, Marketing and PR in Social Media: How the utilization of Instagram builds and maintains customer relationships, Tesis (Swedia: Stockholm University, 2013), hlm. 5.

Tsitsi, et. al.2013 , "The Adoption of Social Media Marketing in South African Banks", European Business Review, vol. 25:4

Yoestini dan Rahma, Eva. S. 2007. Analisis Pengaruh Kualitas Layanan dan Citra Merek terhadap Minat Beli dan Dampaknya pada Keputusan Pembelian.Jurnal Sains Pemasaran Indonesia: Vol. II No.1, P.261-276.

Yoon, S.J., 2012. A Social network approach to the influences of shopping experiences on EWOM. J. Electron. Commer. Res. 13 (3), 213-223.

Zhang, J., Shabbir, R., Pitsaphol, C., \& Hassan, W., 2015. Creating brand equity by leveraging value creation and consumer commitment in online brand communities: a conceptual framework. Int. J. Bus. Manag. 10 (1) 